\title{
An Influence of Gas Explosions on Dynamic Responses of a Single Degree of Freedom Model
}

\author{
Ki-Yeob Kang, ${ }^{1}$ Kwang-Ho Choi, ${ }^{1}$ Jae Woong Choi, ${ }^{2}$ Yong Hee Ryu, ${ }^{2}$ and Jae-Myung Lee \\ ${ }^{1}$ Department of Naval Architecture and Ocean Engineering, Pusan National University, Jangjeon-Dong, \\ Geumjeong-Gu, Busan 609-735, Republic of Korea \\ ${ }^{2}$ Central Research Institute, Samsung Heavy Industries Co., Ltd., Seongnam 13486, Republic of Korea
}

Correspondence should be addressed to Yong Hee Ryu; yh32.ryu@samsung.com and Jae-Myung Lee; jaemlee@pusan.ac.kr

Received 26 November 2015; Revised 11 February 2016; Accepted 11 February 2016

Academic Editor: Guillermo Rus

Copyright (C) 2016 Ki-Yeob Kang et al. This is an open access article distributed under the Creative Commons Attribution License, which permits unrestricted use, distribution, and reproduction in any medium, provided the original work is properly cited.

\begin{abstract}
Explosion risk analysis (ERA) is widely used to derive the dimensioning of accidental loads for design purposes. Computational fluid dynamics (CFD) simulations contribute a key part of an ERA and predict possible blast consequences in a hazardous area. Explosion pressures can vary based on the model geometry, the explosion intensity, and explosion scenarios. Dynamic responses of structures under these explosion loads are dependent on a blast wave profile with respect to the magnitude of pressure, duration, and impulse in both positive and negative phases. Understanding the relationship between explosion load profiles and dynamic responses of the target area is important to mitigate the risk of explosion and perform structural design optimization. In the present study, the results of more than 3,000 CFD simulations were considered, and 1.6 million output files were analyzed using a visual basic for applications (VBA) tool developed to characterize representative loading shapes. Dynamic response of a structure was investigated in both time and frequency domains using the Fast Fourier Transform (FFT) algorithm. In addition, the effects of the residual wave and loading velocity were studied in this paper.
\end{abstract}

\section{Introduction}

An explosion is an extremely rapid release of energy, accompanied by high temperatures and an increased number of moles in the combustion products. The process initiates a fast volume expansion which in most cases results in pressure rise and high flow speeds. Objects in the vicinity of the ignition point are likely exposed to substantial pressure forces depending on their characteristics. As the process proceeds, pressure will propagate into the surroundings as blast wave, which is a layer of compressed air, propagating away from the original ignition point [1]. This blast wave is the main reason for structural damage in explosion accidents [2-4]. Thus, it is very important to predict the load profile by blast wave in order to prevent the explosion damage. However, a correct prediction for blast wave profiles is very difficult, and it is impossible to obtain an accurate pressure data set directly from explosion accidents. Explosion pressures from real accidents are not available because data measurement during the accident is not possible at all. The most practical way to evaluate the explosion pressure is numerical calculation using methods such as computational fluid dynamics (CFD) analysis. Generally, blast wave profiles by CFD analysis are utilized for structural analysis and applied as a loading condition in a computational analysis such as finite element method. The shape of a blast wave profile depends on the characteristics of the structural model in the simulation of an explosion. Thus, the modeling technique for a target structure is very important in order to obtain accurate data [5]. These data can be used for investigation of the dynamic response of structures to blast loading. In structural analysis, single degree of freedom models (SDOF) can be used for many types of structures such as walls, slabs, tubes, and columns [6-8]. These models are evaluated using only one degree of freedom, so they can be inaccurate in terms of quantitative analysis of complex structural response. However, this may be useful tool in qualitative analysis that considers different blast load profiles. Hence, many researchers have carried out the blast analysis using the SDOF model for description of characteristics for structural response subjected to blast load profiles 
TABLE 1: The scenarios for vapour cloud explosion.

\begin{tabular}{llllll}
\hline Module positions & Grid & $\begin{array}{l}\text { Ignition positions } \\
\text { at elevation view }\end{array}$ & $\begin{array}{l}\text { Cloud position } \\
\text { within a module }\end{array}$ & Cloud size & Ignition position \\
\hline (1) A & (1) $0.5 \mathrm{~m}$ & (1) Bottom & (1) Center & (1) $199 \mathrm{~m}^{3}$ & (1) Center \\
(2) B & (2) $1.0 \mathrm{~m}$ & (2) Top & (2) Left & (2) $465 \mathrm{~m}^{3}$ & (2) Same as cloud position \\
(3) C & & & (3) Right & (3) $899 \mathrm{~m}^{3}$ & (3) Left \\
(4) D & & (4) Bottom & (4) $1556 \mathrm{~m}^{3}$ & (4) Right \\
(5) $\mathrm{E}$ & & (5) Top & (5) $2479 \mathrm{~m}^{3}$ & (5) Bottom \\
(6) F & & & (6) $3727 \mathrm{~m}^{3}$ & (6) Top \\
\hline
\end{tabular}

[9-11]. Although there is a large amount of literature available on the characteristics of structural response to dynamic loads, the effect of a blast load profile on the response characteristics of an SDOF model has not been extensively studied. In terms of blast wave profiles, it can occur variously according to the magnitude of pressure, loading duration, loading rate at each domain, and so on. To reflect the diversity of blast load profiles, simplified linear load models are used. It is a triangular shape which is defined by the maximum pressure in each pressure phase and impulse of each phase. The explosion waves were generated by the simulation method using the FLACS, a flame acceleration simulator, and consideration with counting possible cases for each of the factors related to explosion response. In addition, monitoring tool was developed using VBA code in order to analyze the characteristics for explosion load history. The explosion load profiles were divided into two categories and positive pressure phase, negative pressure phase, respectively. The structural response analysis was performed with respect to both time and frequency domains reflecting the variation of load profiles.

\section{Gas Explosion Analysis}

2.1. Blast Overpressure. When a large scale explosion occurs, blast overpressure is a major hazard in offshore plants as well as other structures associated with combustible gas and flammable materials. Thus, it is essential design process to withstand the blast overpressure in a FPSO topside module. This pressure profile over time of gas explosion can be determined by the motion of blast wave, and it is divided into the phase of expansion and suction [12]. In expansion phase, the atmospheric pressure increases dramatically to a peak value, but it does not always increase linearly; it is often fluctuated. However, this effect may be ignored because fluctuation is dissipated quickly, so only the initial expansion or suction is important [13]. In this study, a range of explosion simulation was carried out in order to investigate for characteristics about blast overpressure at each condition.

2.2. Simulation for Explosion of Vapour Cloud. Dispersion and ventilation analyses are very important to control the risk of gas explosions in offshore installations. First, in case of ventilation, wind speed was estimated based on a linear correlation assumption between external wind speed and internal flow. By using the results of ventilation analysis, dispersion analysis was carried out in order to determine the spread of released gas under various conditions based on a defined number of wind directions, speeds, ventilation, observations about equipment, and the geometry in the areas. The leak representation was also based on a preventative range of possible combinations of leak parameters and includes variations in directions relative to the wind directions, leaks impinging on objects, free field jets, and diffusive leaks. The leak locations were chosen to be close to specific equipment or in an area with several leak sources. Eight different leak rates such as $0.75 \mathrm{~kg} / \mathrm{s}, 1.5 \mathrm{~kg} / \mathrm{s}, 3.0 \mathrm{~kg} / \mathrm{s}, 6 \mathrm{~kg} / \mathrm{s}, 12 \mathrm{~kg} / \mathrm{s}, 24 \mathrm{~kg} / \mathrm{s}, 48 \mathrm{~kg} / \mathrm{s}$, and $96 \mathrm{~kg} / \mathrm{s}$ are simulated for each leak location. Six release directions such as $+/-\mathrm{X},+/-\mathrm{Y}$, and $+/-\mathrm{Z}$ and diffusive release condition are considered for specific leak locations. The vapour cloud explosion simulations were carried out considering the results from the ventilation and dispersion analysis. The purpose of the explosion analysis is to identify potential explosion loads in the areas of concern. A number of explosion simulations were carried by the FLACS software, which is one of the best validated tools for modeling flammable and toxic releases in the technical safety context in the oil and gas field $[14,15]$. These simulations were considered to various gas cloud sizes, gas cloud locations, and ignition locations described in Table 1 . The gas clouds were of homogeneous stoichiometric concentration, and two different types of monitors were used to record blast load profiles as shown in Figure 1. 1000-point monitors were uniformly distributed over the entire process area at a space of 3 meters, while $3 \times 3\left(\mathrm{~m}^{2}\right)$, local panel monitors were distributed on blast walls and decks.

2.3. FLACS Model: FPSO Topside Platform. A series of CFD analysis was performed using a full-scale FPSO topside model including detailed parts of pipes and equipments, and the time history data of the blast loads at monitor points and panels were obtained by the analyses. In CFD analyses, all fire and blast walls were assumed to be rigid and unfailing during the explosions; namely, the walls did not deform under the design explosion loads. The blast pressure might be somewhat overestimated because the blast wave could travel over the deformed structures with angle. Plated decks are assumed to be solid and unyielding, while grated decks are assumed to be $50 \%$ open and remain in place during the explosion. Figure 1 shows the geometrical floating production, storage, and offloading (FPSO) model used in this study for vapour cloud explosion simulation. The FPSO can be divided into two main areas under the influence of explosion. One is turret 

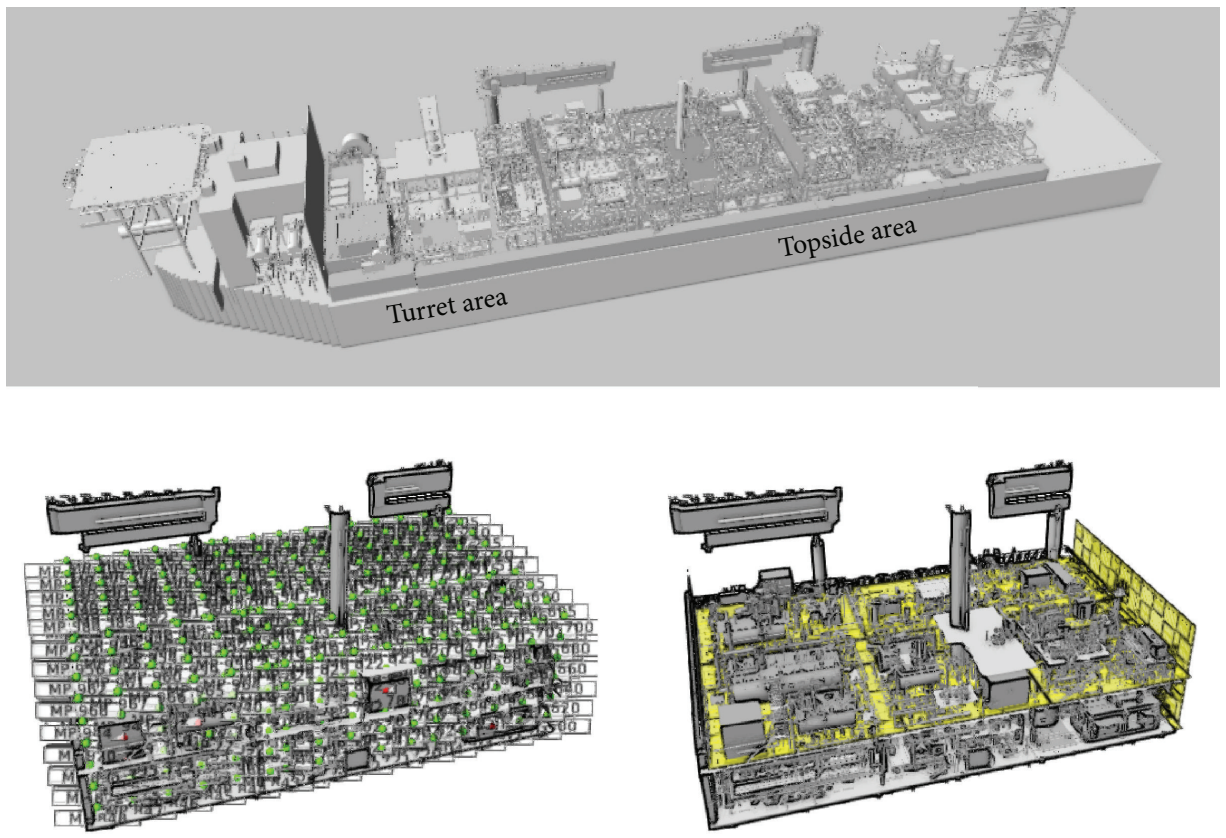

FIGURE 1: Separation of module and monitoring position.

area and the other is topside area. The turret is moored to the seabed with chains, wires, and anchors. In addition, it allows the FPSO to adopt the direction of the least resistance against wave, wind, and currents [16]. The topside area consists of a process system and a utility system. The process system has a variety of combustible substance and flammable materials so that the probability of explosion is much higher than utility system [17]. These main characteristics of FPSO were reflected in this model. Since the modeling details are the most critical factor affecting the overpressure response, the $3 \mathrm{D}$ models approved for construction were considered in this study including minor obstacles such as small piping, stairs, handrails, and instruments as well as all the equipment and structures on the topside of the FPSO for CFD simulations.

\section{FLACS Output Data Analysis}

3.1. Development of Data Process Tool. In present study, to measure the explosion pressure data, 1000-point monitors are uniformly distributed over the entire process area at a space of 3 meters from the process deck and blast walls. In addition, 206-panel monitors are distributed equally on blast walls and decks. Hence, many different kinds of explosion wave profiles were acquired, and then computational tool using VBA code was developed to monitor these enormous output data. Figure 2 shows the procedure for gas explosion data analysis using developed VBA code. First of all, CFD analysis performs considering the explosion simulation affecting parameters such as ignition position, cloud size and position, and data types. The next stage is to sort and process the FLACS output data considering the desired information of explosion load profiles. Generally, explosion design load is determined by two values in the peak pressure and each impulse which is the area under a transient wave profiles.
Thus, the VBA code provides the core functions which can bring the information values of output data, and it is able to compare these values according to scenarios and data types. The explosion load profiles were simplified to triangle shape which was generated by using the equivalent peak pressure and impulse. This is because of the time effective method in structural analysis. The developed VBA code can plot this simplified model considering each pressure wave parameter.

3.2. Quantitative Analysis. The intensity of overpressure is a core factor in the evaluation of an explosion wave profile. Overpressure in the process area (as shown in Figure 3) was measured through gas explosion simulations by using the CFD software, and all output data were analyzed using the developed VBA code. Figure 4 shows the maximum overpressures measured in the process area based on the gas cloud volumes of $199 \mathrm{~m}^{3}, 465 \mathrm{~m}^{3}, 899 \mathrm{~m}^{3}, 1556 \mathrm{~m}^{3}, 2479 \mathrm{~m}^{3}$, $3727 \mathrm{~m}^{3}$, and $5314 \mathrm{~m}^{3}$. To easily compare the intensity of overpressure, the average overpressures with respect to each gas cloud volume were normalized by the maximum overpressure, which is observed at a gas cloud volume of $3,727 \mathrm{~m}^{3}$ at the process-turret wall. Figure 4(a) shows the maximum overpressure at the two blast walls between the utilityprocess area and the process-turret area, and Figure 4(b) shows the difference of overpressure intensity of modules in the process area. Both figures indicate that the gas cloud volume size directly influences the intensity of overpressure, and overpressure toward the turret area is higher than that on the other side. This is because congestion in modules M410 and M430 is much higher than that of other modules (see Figure 3), indicating that fluid interaction on small- and medium-sized objects increases the intensity of explosion pressures. This relationship between the level of congestion 


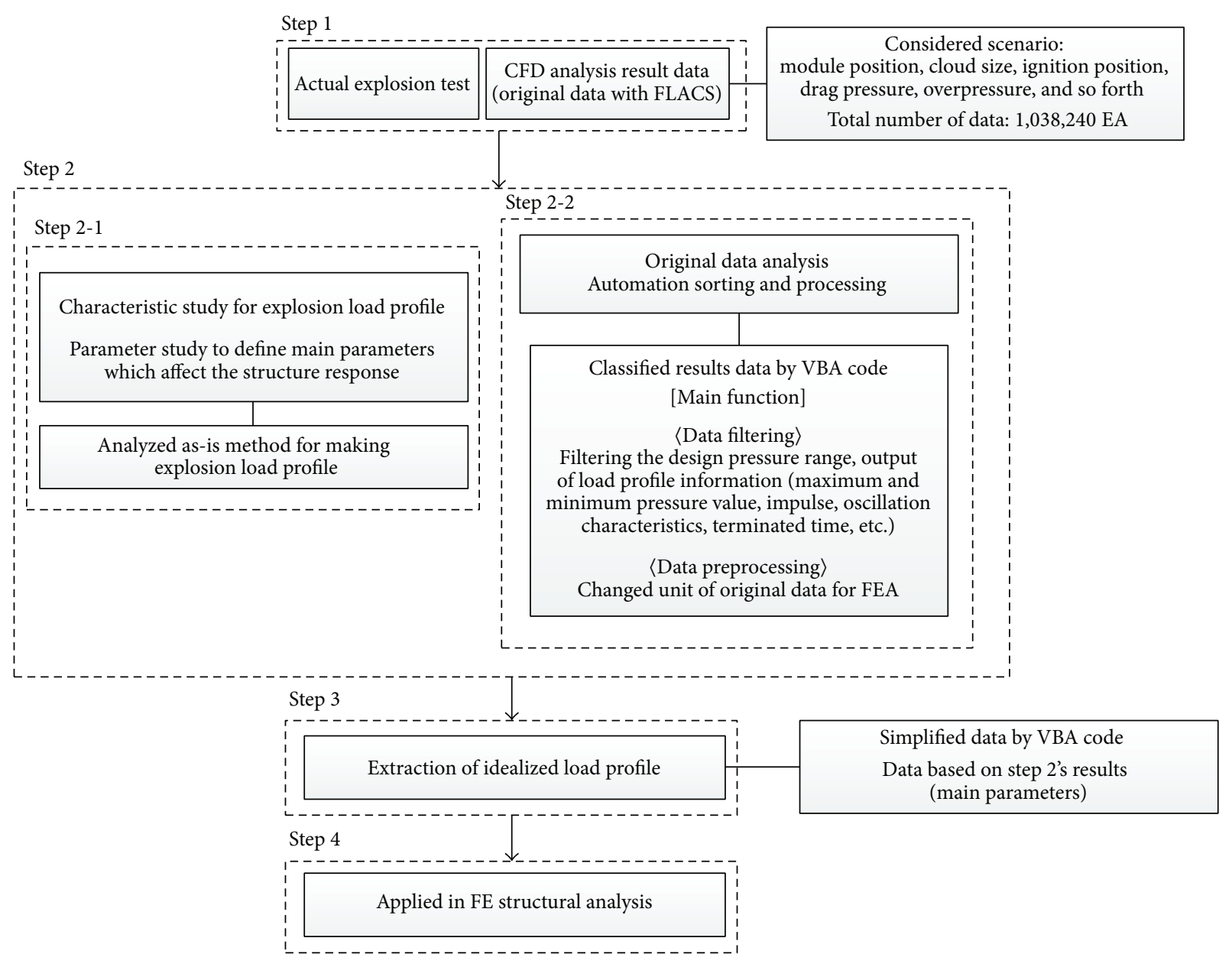

FIGURE 2: Algorithm for gas explosion data analysis using developed VBA code.

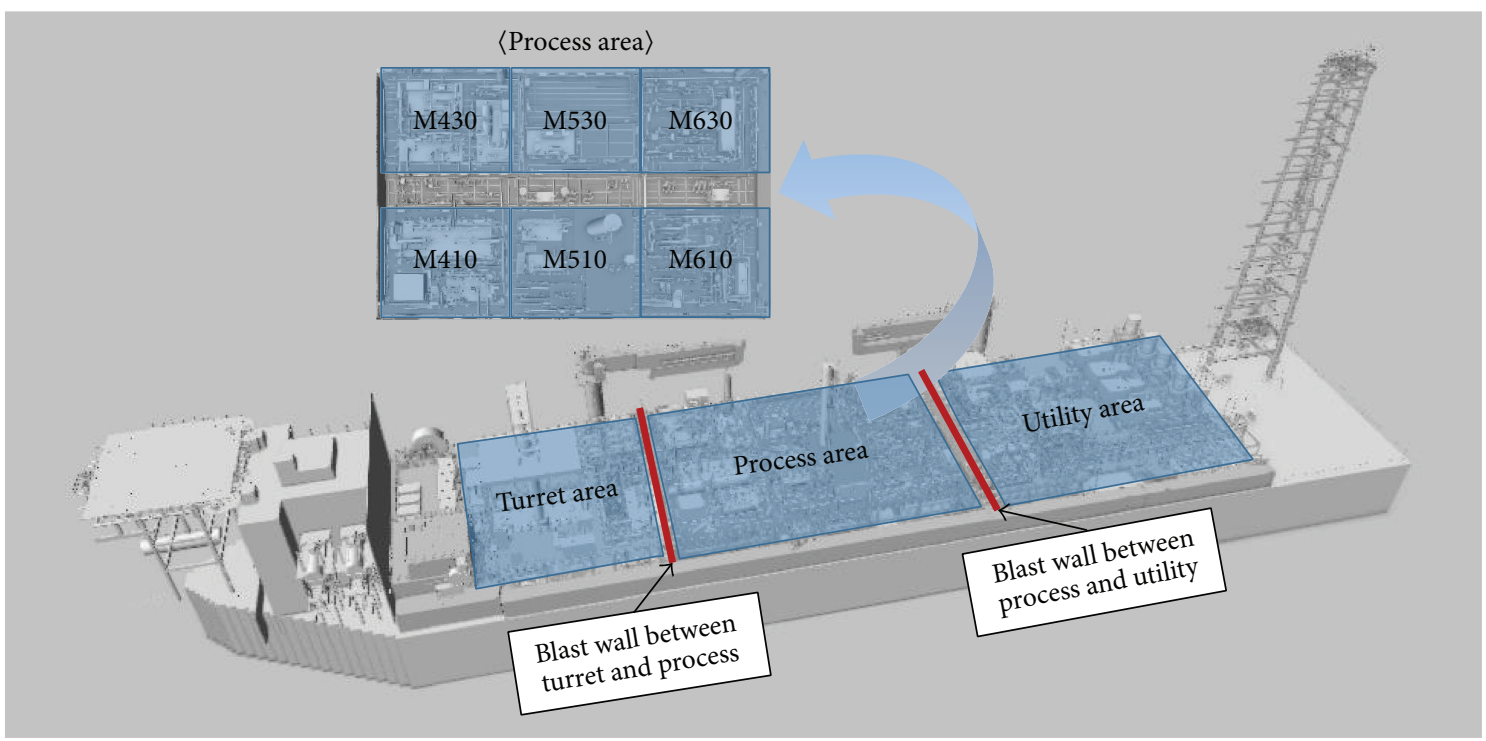

FIgURE 3: Layout of FPSO. 


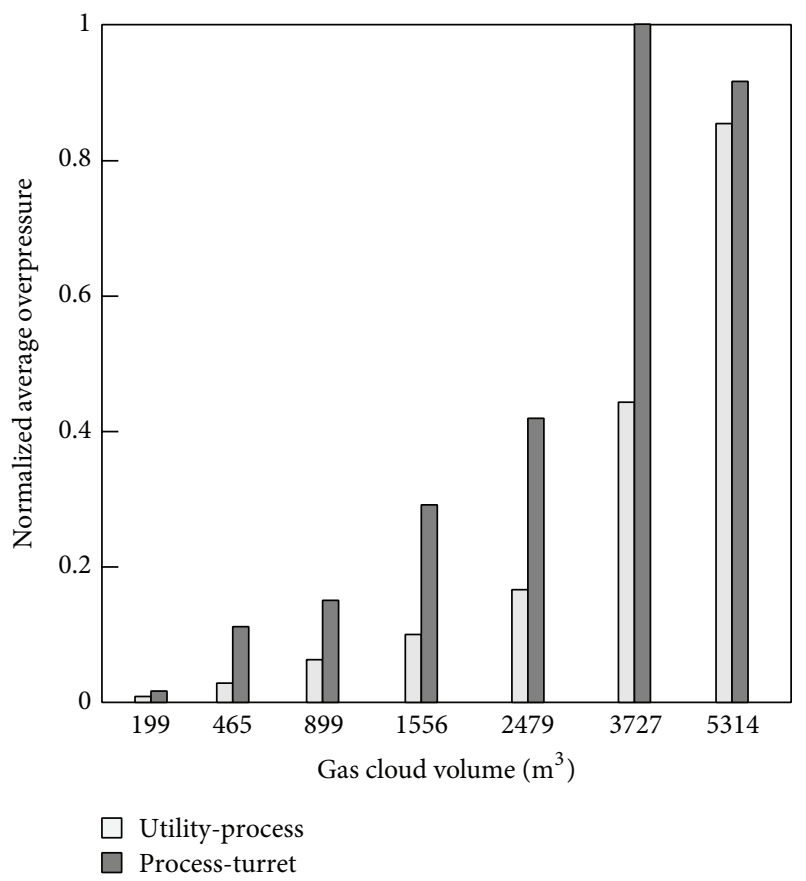

(a)

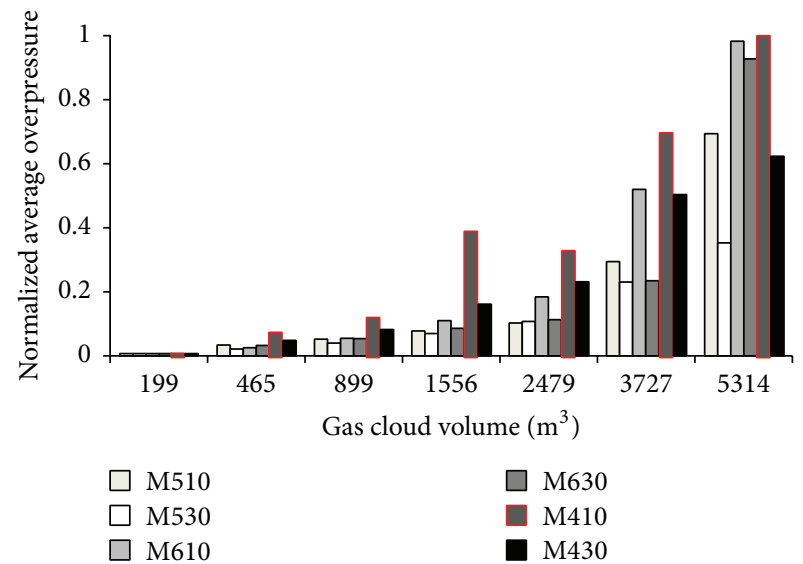

(b)

Figure 4: The difference of maximum overpressures according to the gas cloud volume in specific positions. (a) Comparison between utilityprocess and process-turret area. (b) Comparison at the modules.

and the intensity of overpressure was studied by Chille et al. [18]. They reported that the peak overpressure under a complex geometry condition was significantly higher than that under a simple geometry condition. Thus, to reduce structural damage due to blast pressure loads, it is important to retain sufficient space for the transportation of an explosion wave.

\subsection{The Relationship between Positive Pressure and Negative} Pressure. It is a controversial issue to include the negative phase in the pressure-time history in the blast analysis of structures. The negative pressure was often neglected by assuming that it may be insignificant to the dynamic response of structures in blast analysis and design $[19,20]$. However, the negative pressure sometimes is quite significant and cannot be neglected. In addition, the interaction between the negative part of the blast wave and the response of the structure response is important. In this study, the relationship between the positive and negative peak pressures in an explosion load profile was investigated by analyzing explosion simulation results. The relationship between the positive and negative pressures in all explosion scenarios is illustrated for different data types in Figure 5. The quantitative distributions of the positive and negative pressures based on the normalized values are plotted in black and red dots, respectively. Although the negative pressure is lower than the positive pressure for most data, the magnitude of negative pressure is similar to that of the positive pressure in some cases. For the point-pressure (NP) data, the magnitude of the negative pressure is similar to that of the positive pressure for a relatively small pressure range as shown in Figure 6(a). Figure 6(b) also shows the results of panel-pressure (NPP) data, and the value of negative pressure is higher compared to that in the pointpressure (NP) data. The formation of the negative phase in a pressure wave highly depends on the geometry condition. For example, the tunnel scenarios represent an extreme case to form the negative pressure. If the gas cloud is ignited in a tunnel with a closed end, there will be overpressure first. Once the pressure propagates to the opening, a high negative pressure will propagate back in. The offshore topside has a high level of congestion and confinement to build the negative pressure at some locations. A positive peak pressure of $0.02-0.07 \mathrm{MPa}$ is normally considered as design explosion loads in offshore industries [21]. It should be noted that the negative phase in a pressure-time history model should be included for accurate blast analysis and structural assessment if the intensity of the negative pressure is considerably high (when defining the design blast pressure).

3.4. Fast Fourier Transform Analysis. To investigate the effect of pressure intensity at each phase, a Fast Fourier Transform (FFT) analysis was performed using the MATLAB software. The applied load was converted from the time domain to the frequency domain in order to perform a spectrum analysis by using the FFT method. A Fourier analysis is one of the useful solutions to determine a representative frequency domain from an arbitrary signal and provides information to understand the characteristics of the signal [22]. This method can analyze the frequency characteristics of a system by measuring the transformed response of the system based on 


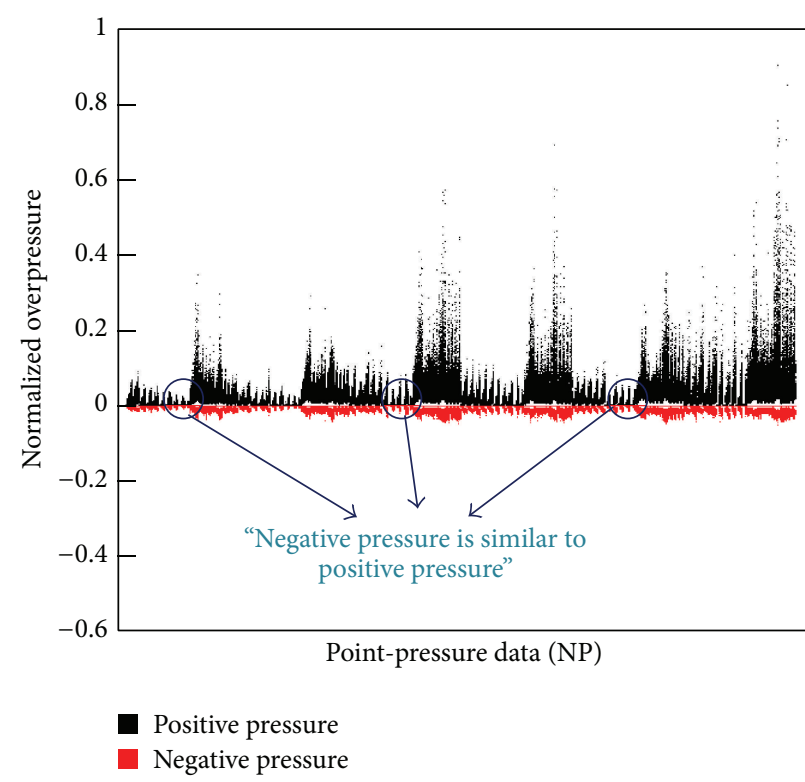

(a)

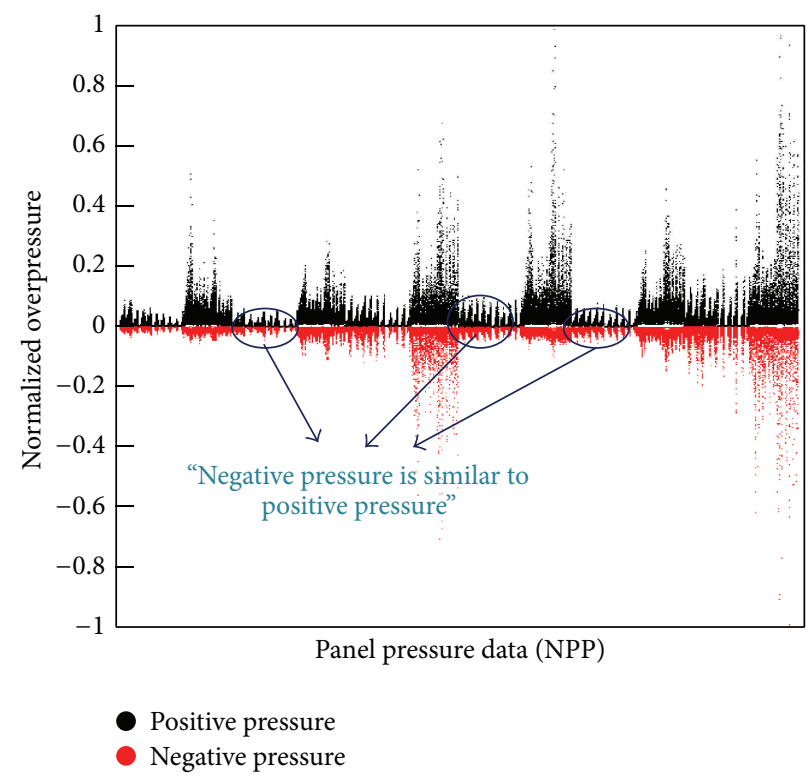

(b)

FIGURE 5: The comparison between positive and negative overpressure according to data types: (a) point pressure data type and (b) panel pressure data type.

the specific input function. The FFT analysis was performed to investigate the dynamic response of the SDOF model in the frequency domain, considering the variation of the positive and negative peaks in this study. The top graphs in Figures 6 and 7 indicate the input load profiles in the time domain, and the bottom graphs show their FFT results, the input load in the frequency domain, and the maximum displacements of the SDOF models regarding each frequency level. To clearly compare the magnitude of the maximum load in the same phase, the absolute values of the negative and positive loads were plotted, as shown by the black lines in each figure. Figures 6 and 7 present the FFT results for controlling the positive and negative maximum loads, respectively. The maximum displacement obtained by performing dynamic analyses, using the SDOF models, shows that not only the magnitude of the positive phase but also the magnitude of the negative phase affects the dynamic response of the system when the impulse of the negative phase is relatively large. It should be noted that the dominant area in the frequency domain (i.e., $\sim 6 \mathrm{~Hz}$ ) was observed at the end of the input load.

\section{Dynamic Response Analysis}

4.1. SDOF Model. The characteristics of the structural response subjected to blast load have been analyzed using a SDOF model that can be described by a single mass connected to a spring. This mass can only move along the spring elongation direction. Generally, SDOF models are often used to approximately understand the dynamic response mechanism for a complex structural system [23]. When the motion of SDOF models is related to explosion acceleration, $\ddot{x}(t)$ is considered.
The equation for this motion can be described as follows:

$$
m \ddot{x}(t)+c \dot{x}(t)+k x(t)=F[x(t)] .
$$

Substitute $w_{n}=\sqrt{k / m}$ and $\zeta=c / 2 m w_{n}=c / c_{\mathrm{cr}}$.

Equation (1) can be rewritten as

$$
\begin{aligned}
\ddot{x}(t)+2 \zeta w_{n} \dot{x}(t)+w_{n}^{2} x(t) & =\frac{F[x(t)]}{m}, \\
c_{\mathrm{cr}} & =2 m w_{n}=2 \sqrt{k m}=\frac{2 k}{w_{n}}, \\
T_{D} & =\frac{T_{n}}{\sqrt{1-\zeta^{2}}},
\end{aligned}
$$

where $x(t)$ is the displacement of SDOF model and $\dot{x}(t)$ and $\ddot{x}(t)$ mean the mass velocity and mass acceleration by explosion loading. In addition, $w_{n}$ is the natural frequency of the SDOF model and $\zeta$ is the ratio of the damping of the model to the critical value $\left(c_{\mathrm{cr}}\right)$. The damping constant $c$ is a measure of the energy dissipated in one cycle of free vibration. Equation (4) shows the relationship between the natural period of the damped vibration and the natural period without damping. From this equation, it is inferred that the natural period $\left(T_{n}\right)$ and the natural period of damped vibration $\left(T_{D}\right)$ are almost the same if the damping ratio is small. It should be noted that the damping effect can be very small when studying the critical response of structures under the drastic increase/decrease of load in sudden time such as gas explosion load [13]. Hence, the characteristics of dynamic response by explosion loads were analyzed using the undamped single degree of freedom model in this study. 

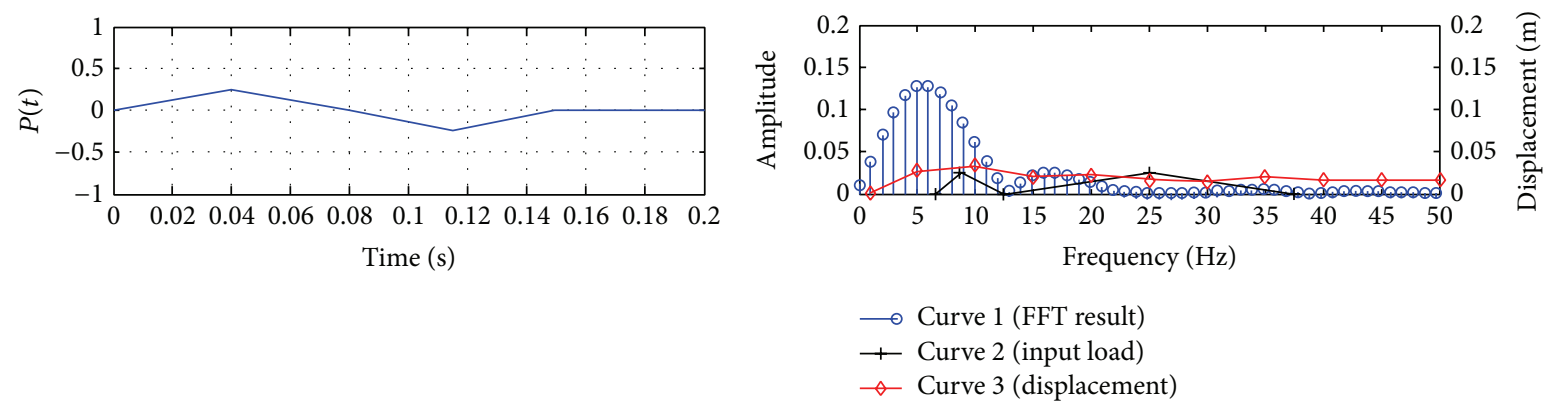

(a)
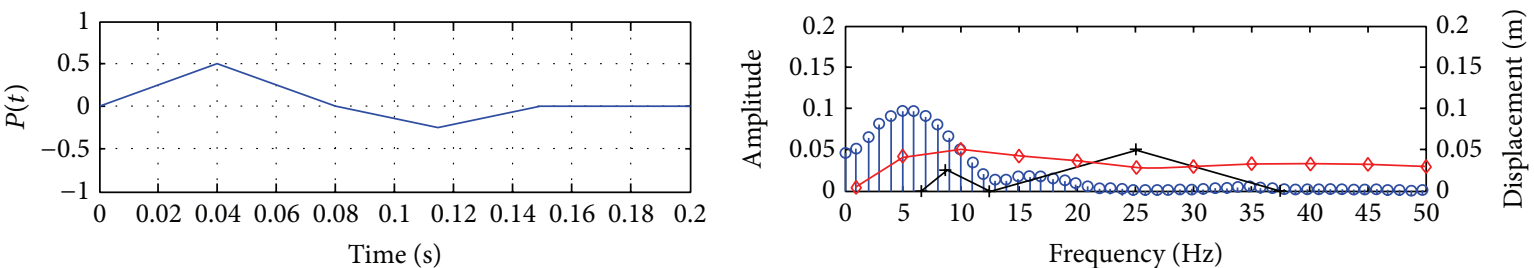

$\longrightarrow$ Curve 1 (FFT result)

+ Curve 2 (input load)

$\rightarrow$ Curve 3 (displacement)

(b)
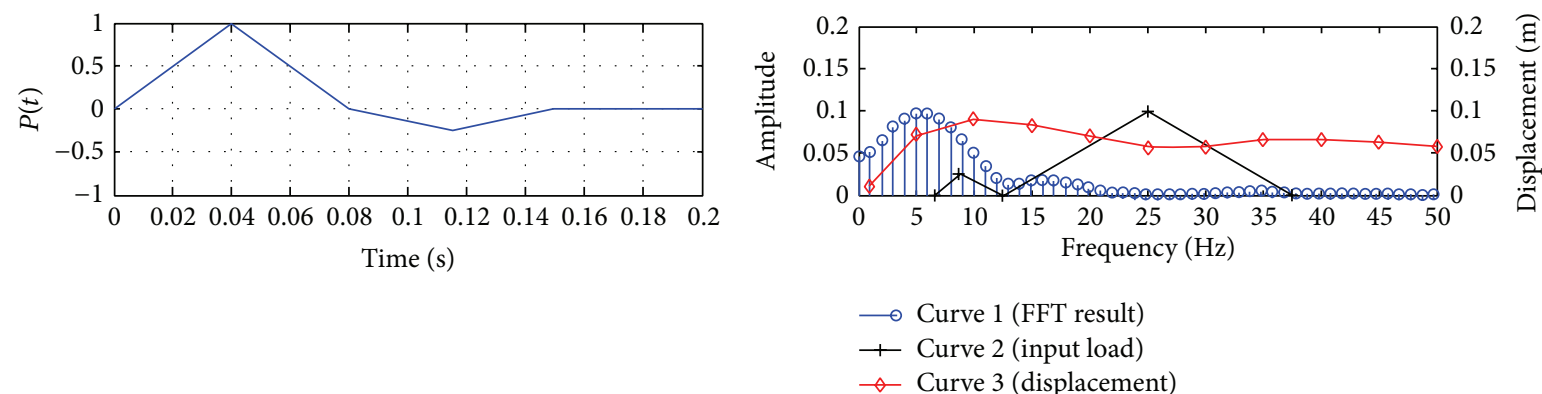

(c)

FIgURE 6: Fast Fourier Transform analysis considering the magnitude of maximum load in positive pressure phase. (a) Standard data. (b) Increasing the 2 times of positive maximum load. (c) Increasing the 4 times of positive maximum load.

TABLE 2: Detailed properties of SDOF.

\begin{tabular}{|c|c|c|c|c|c|c|c|}
\hline \multicolumn{2}{|l|}{ Cross section } & Breadth (m) & Height (m) & Length (m) & $\begin{array}{l}\text { Geometrical moment } \\
\text { of inertia }\left(\mathrm{m}^{4}\right)\end{array}$ & $\begin{array}{l}\text { Elastic Modulus } \\
\qquad(\mathrm{MPa})\end{array}$ & Density $\left(\mathrm{kg} / \mathrm{m}^{3}\right)$ \\
\hline$\stackrel{b}{\longleftrightarrow} \mid$ & & & & & & & \\
\hline & $h$ & 0.1 & 0.1 & 1 & $8.33 \cdot 10^{-6}$ & $2.07 \cdot 10^{5}$ & 7830 \\
\hline
\end{tabular}

Figure 8 shows the composition of the SDOF model including boundary and loading conditions. As shown in this figure, node 1 was fixed, while the other one was accelerated by applying the blast loading conditions. Figure 9 shows the loading condition in this analysis. Pressure-time curve can be simplified to triangular impulse types; however, the impulse, which represents the integrated area under the pressure-time curve, is equal. Table 2 shows detailed properties of single degree of freedom model.

4.2. Residual Wave Effect. The blast load profiles can be expressed in various forms. Sometimes, the cyclic types sequentially repeat the positive and negative pressure phases, and the maximum overpressure emerges after this cyclic section, 

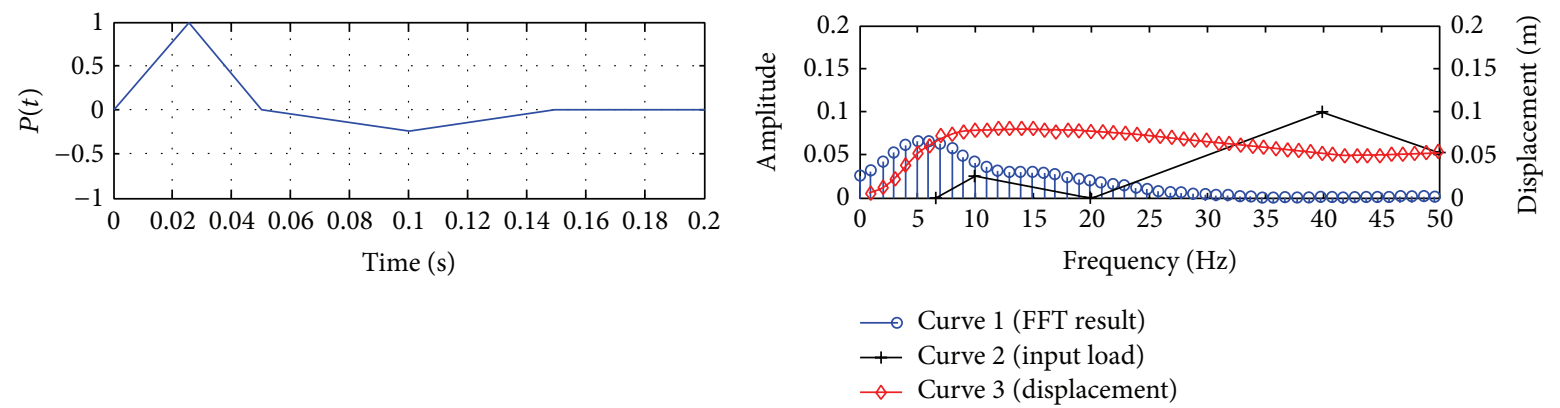

(a)
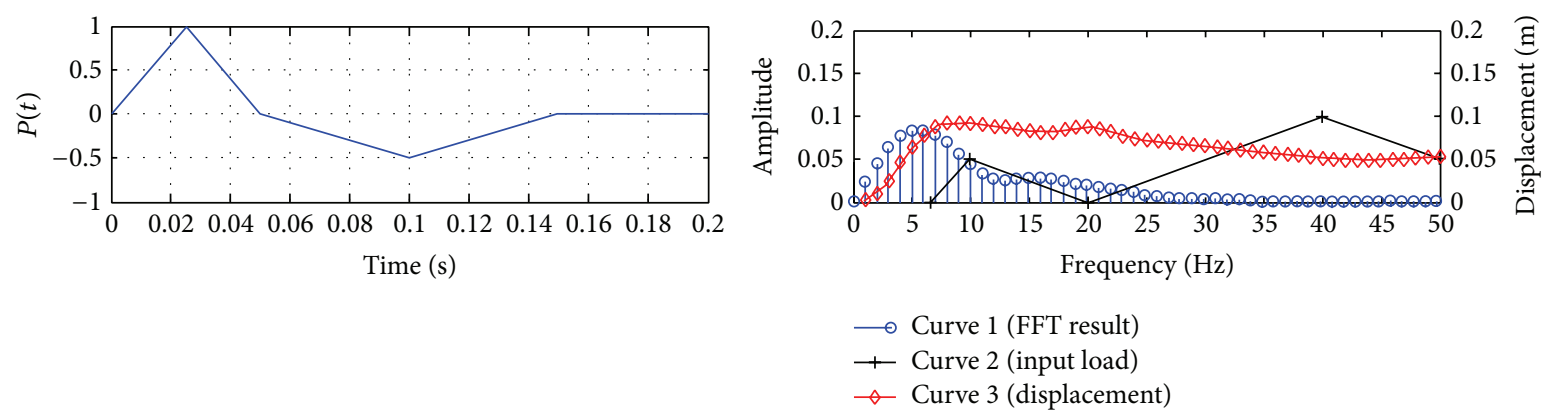

(b)
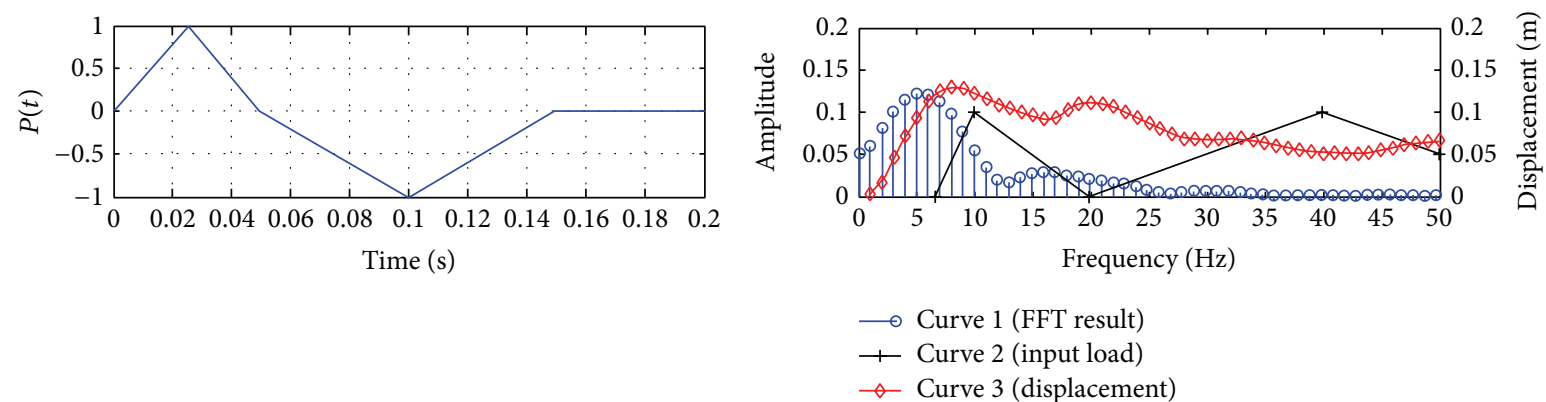

(c)

Figure 7: Fast Fourier Transform analysis considering the magnitude of maximum load in negative pressure phase. (a) Standard data. (b) Increasing the 2 times of negative maximum load. (c) Increasing the 4 times of negative maximum load.

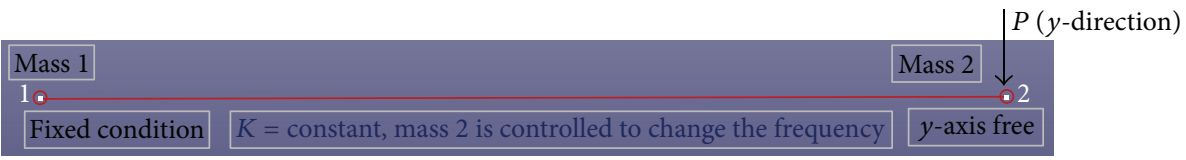

Figure 8: Composition of single degree of freedom model.

as described in Figure 10. However, the maximum pressure value is generally indicated in the first section of the wave profile. Hence, it is very difficult to generalize the characteristics of the blast wave profile because of its arbitrary shape. An extensive analysis of FLACS output data revealed that the load shapes are similar to those shown in Figure 10(a) in a relatively less complex area which is far from the ignition position (more than $30 \mathrm{~m}$ ). Industrial structures which requested blast resistant design are constructed based on maximum overpressure about $0.02 \mathrm{MPa}$. Generally, these blast load profiles have a main wave that is composed of relatively strong two pressure phases compared to other waves. Consequently, the blast wave data specified in Figure 10(a) were almost of zero value. In other words, they are insignificant that they did not cause damage to structural system. Hence, target data of cyclic shape can be generalized as shown in Figure 10(b). As mentioned above, they have a main wave and residual waves. In this study, these residual waves' effect on structural dynamic response was investigated. To do this, the data that have three cycle pressure phases were selected as described in Figure 11(a). The peak pressures after the third cycle were very small, so these pressure phases were not considered 

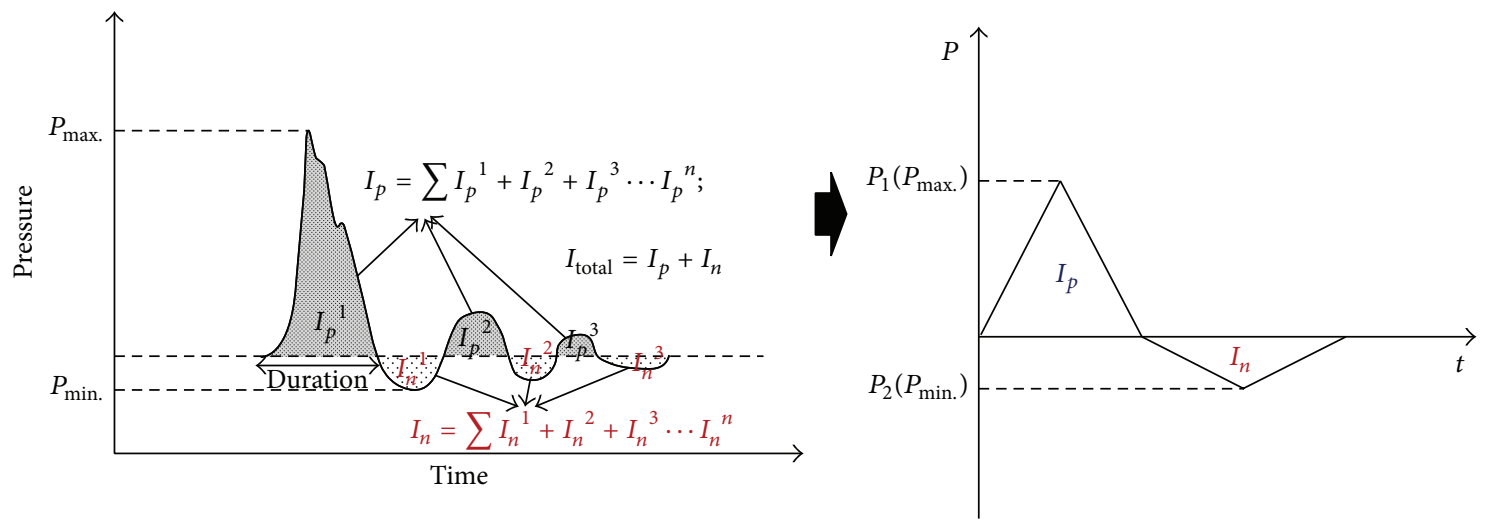

FIGURE 9: Loading condition of single degree of freedom.

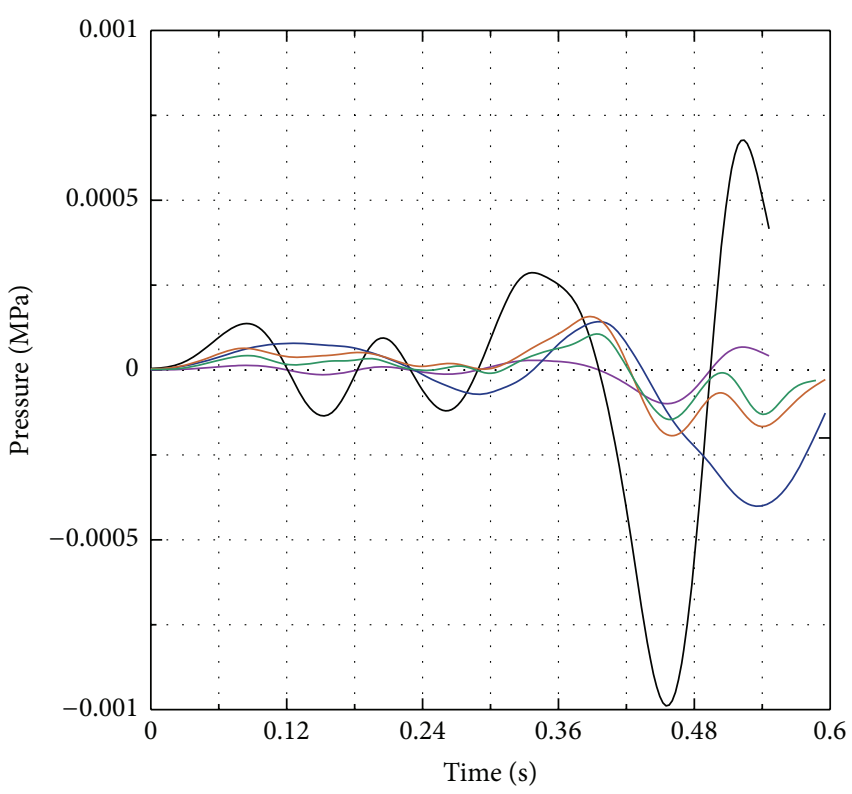

Unusual cyclic wave

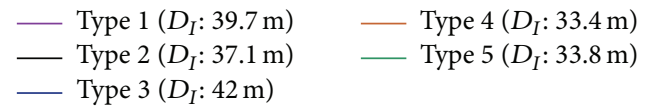

(a)

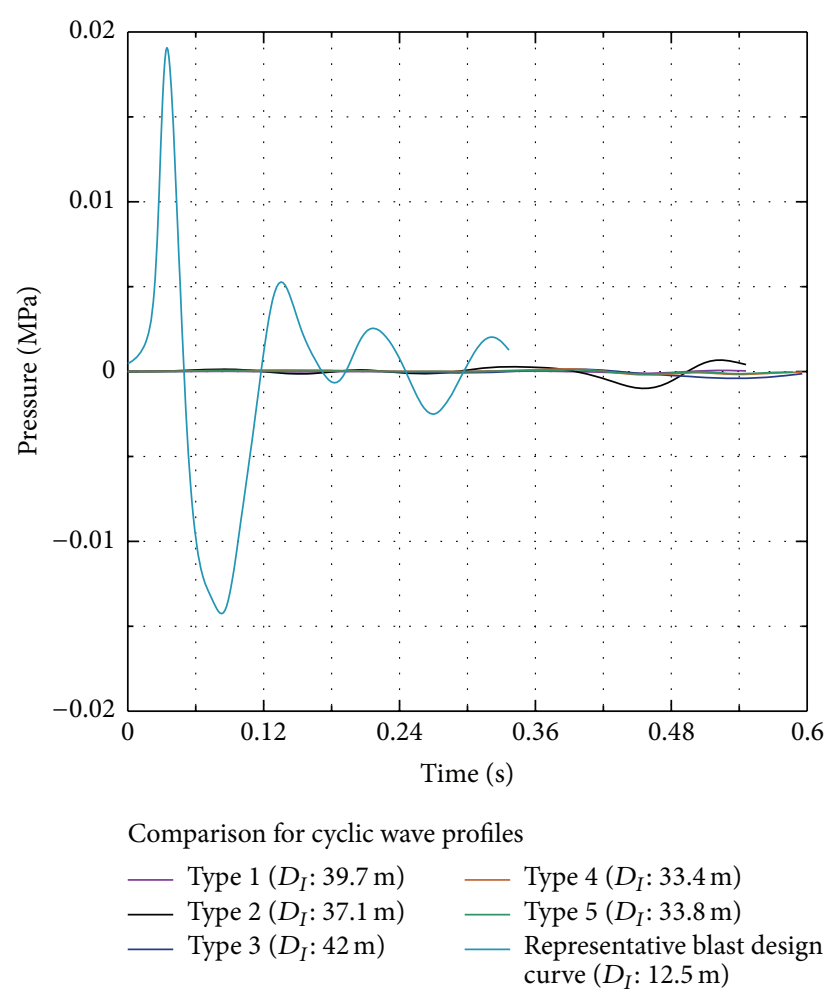

(b)

FIGURE 10: A variety of cyclic types in blast wave profiles. (a) In small pressure range. (b) Representative blast wave of cyclic type.

in residual wave effect analysis. Figure 11(b) shows the list of target data which are monitored by using the developed VBA code, and then the most severe two cases were selected based on the maximum pressure in pressure phases of second period. The values in Figure 12, 20\%, and 30\%, respectively, mean that the maximum pressures in second phase are $20 \%$ and $30 \%$ compared to maximum value in main phase. This loading condition was applied to investigate the residual effect on structural response. A series of analysis were carried out considering the number of cycles and duration according to cycles. Figure 12 shows the comparison results between only applying the main wave and considering the other residual waves. The normalized displacement, $Y_{m} /(P / k)$, is shown against the normalized time $(t d / T n)$ in the figure. $P / k$ is the static deformation; $T_{d}$ means the loading duration; and $T_{n}$ is the natural period of the single degree of freedom model. Figure 12(a) indicates the displacement response of single degree of freedom (SDOF) model considering the loading condition which has the two cycles, and Figure 12(b) shows the results considering the three cycle waves according to maximum pressure values in second phase. The frequency and magnitude of the first cyclic wave are the most important 


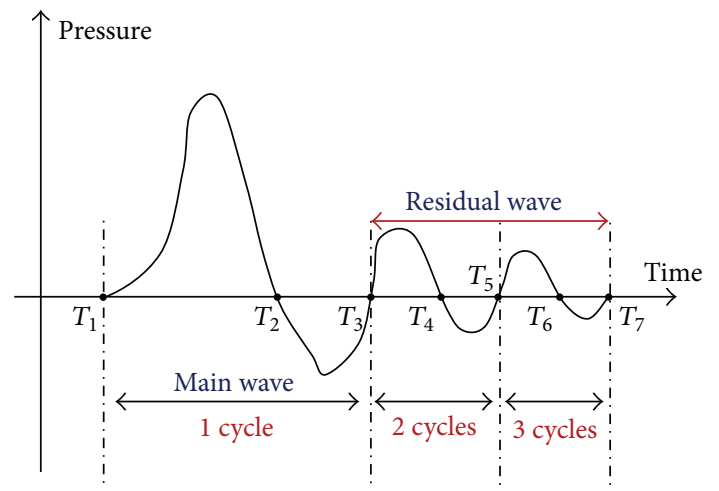

(a)

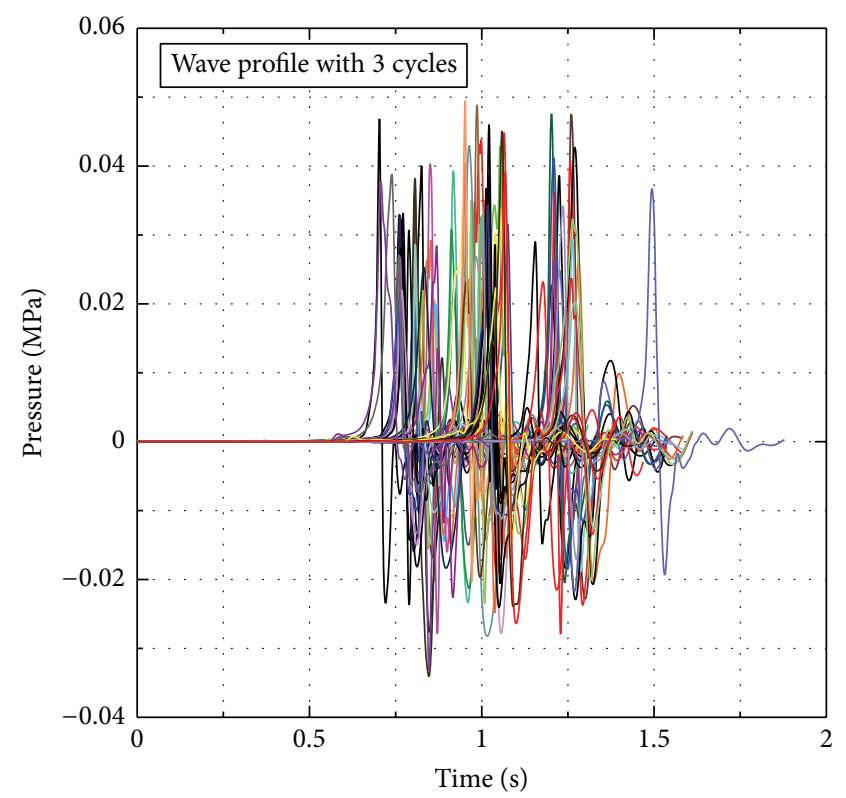

(b)

FIgURE 11: Residual waves effect analysis. (a) The standard for the cyclic wave profiles. (b) Extraction of target data by VBA code.

factor of all the explosion wave profiles, and secondary and third residual waves may be neglected in qualitative analysis as long as the resonance effect is negligible.

4.3. The Effect for Difference of Loading Rate. The dynamic loads such as explosion wave show the very different load profiles according to explosion affecting parameters which mean source of explosion, geometrical characteristics of target structure, wind direction/speed, and so on. The peak overpressure and loading durations are most sensitive things related to these parameters. The time taken to reach the peak overpressure, especially, is very important. This is because the pressure by explosion wave is applied to structural body for an extremely short time. Thus, difference of explosion loading velocity can be a core element in structural damage and deformation [24]. In this study, a series of analysis have been performed to assess the effect of loading velocity on structural dynamic response. To do this, three types of triangular pulse loadings which have different loading velocity were applied to the single degree of freedom model. Figure 13(a) shows the results of peak displacement results considering the loading velocity of positive pressure phase, and Figure 13(b) means the same results according to the loading velocity of negative pressure phase. The $y_{m} / y_{\mathrm{el}}$ means the normalized maximum displacement, where $y_{m}$ is the maximum displacement of SDOF model, and $y_{\text {el }}$ means the static deformation at the yielding point due to applied loads. As shown in Figure 13, the loading velocity was affected by structural response, but it shows the different effect in each pressure phase. In case of positive pressure phase, loading velocity has a profound effect on response of SDOF model. Although it is less important considering relatively short loading compared to the natural period of structural system, it is influential in opposite case.
When the loading duration is longer than natural period, namely, the value of $t_{d} / T_{n}$ is bigger than two, these loads generate the bigger displacement with faster loading velocity. However, the loading velocity in negative pressure phase has little impact on structural response as shown in Figure 13(b). As a result, it is obvious that the positive pressure phase has a bigger impact on structural member than negative pressure, and for the faster loading velocity, the bigger displacement occurred if $t_{d} / T_{n}$ is bigger than two.

\section{Results}

In the present study, qualitative analyses of the dynamic response of structures subjected to various types of gas explosion loads were performed. Firstly, the extensive data analysis from CFD explosion simulations was carried out to investigate the characteristics of explosion load profiles. In this work, we evaluated various aspects of the profile parameters (i.e., the magnitude of overpressure, the relationship between positive pressure and negative pressure, and the shapes of explosion load profiles) using a monitoring tool that was developed using VBA code. Secondly, the characteristics of dynamic responses to considerable explosion load profiles were analyzed using a single degree of freedom model. The staple results from this research are summarized as follows:

(i) The relationship between overpressure and congestion degree was found. Higher overpressures were produced by more congested areas than by less congested areas. The influence of the blast reflection can be minimized in less congested areas. Thus, it is important to retain proper clearance in hazardous facilities.

(ii) Negative pressures must be considered in blast analyses to obtain accurate performance of the structure. 


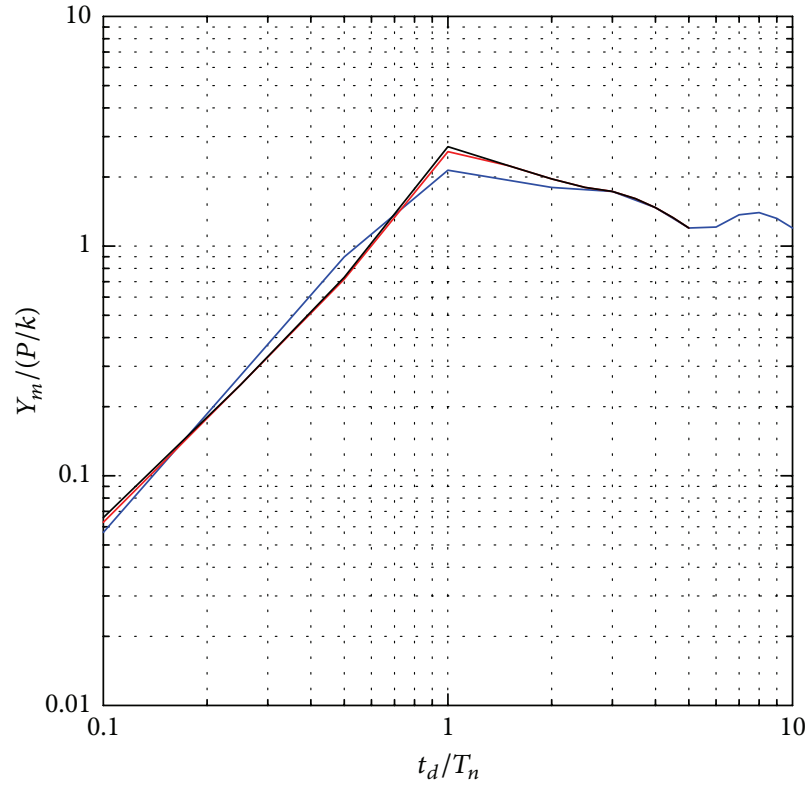

Residual wave effect

1 cycle
-2 cycles $(20 \%)$
-2 cycles $(30 \%)$

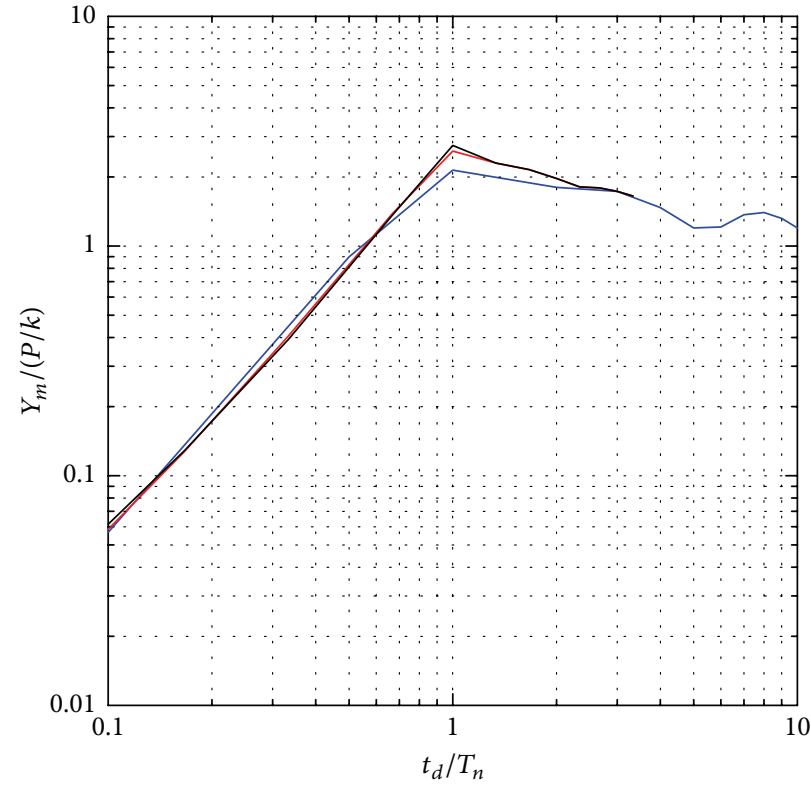

Residual wave effect

1 cycle

- 3 cycles $(20 \%)$

- 3 cycles (30\%)

(a)

(b)

FIGURE 12: The results for maximum displacement response of single degree of freedom model according to the number of cycles: (a) 2 cycles; (b) 3 cycles.

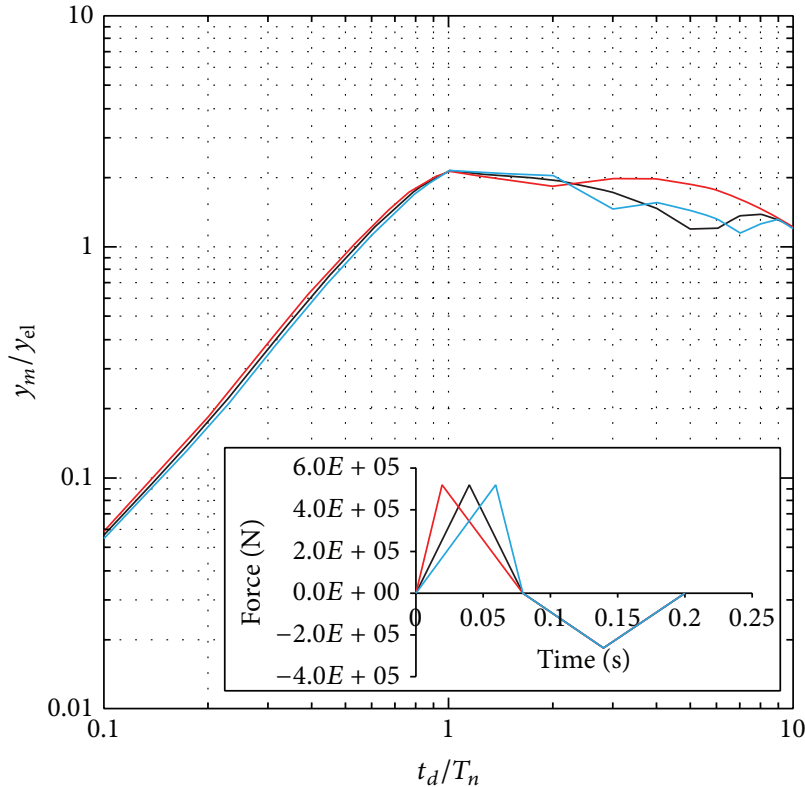

(a)

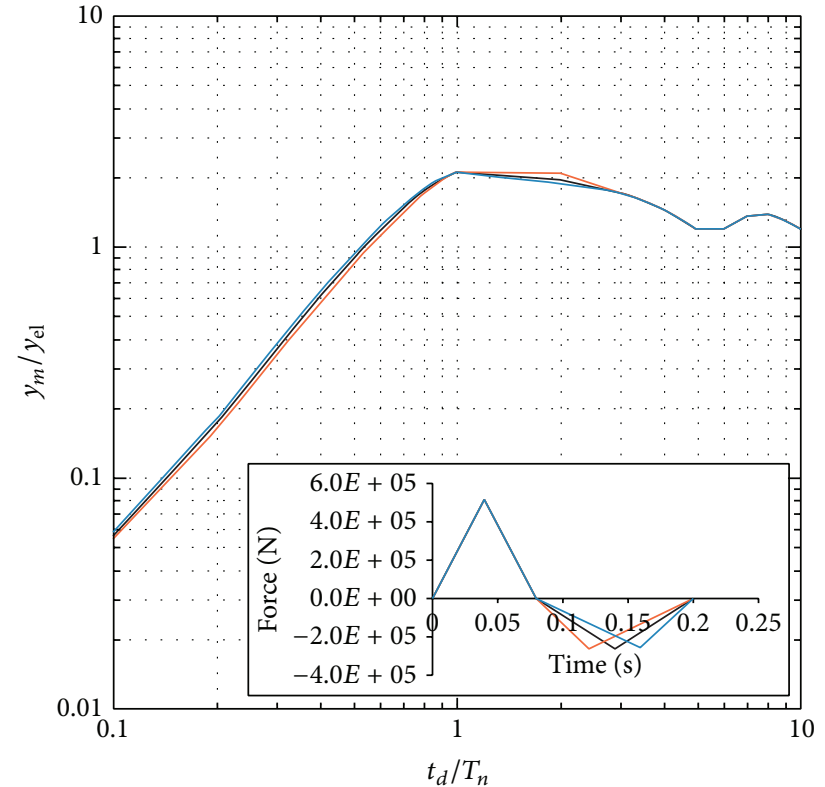

(b)

FIGURE 13: The analysis for the effect of loading rate (a) according to loading velocity of positive phase and (b) according to loading velocity of negative phase. 
In some cases, the influence of including the negative phase can be considerable compared to using only positive pressure. The influence of negative pressure is close to that of positive pressure in the intensity range of $0.02-0.05 \mathrm{MPa}$ and should be considered in the development of a load profile for offshore industries in this range.

(iii) The Fast Fourier Transform (FFT) analysis was performed to characterize the dynamic response of the single degree of freedom (SDOF) model in the frequency domain corresponding to the intensity of explosion pressures in each phase. Through this analysis, it was found that the intensity of pressure in positive phase was a more dominant factor than in negative phase with respect to the dynamic response of the SDOF model.

(iv) The residual wave effect on structural dynamic response was investigated. The frequency and magnitude of the first cyclic wave are the most important factor of all the explosion wave profiles. Secondary and third residual waves may be neglected in qualitative analysis as long as the resonance effect is negligible.

(v) The loading velocity can be one of the main concerns on structural response, but the structure response due to the loading velocity differed in different phases. More deformation was caused by a higher loading velocity in the positive pressure phase, while the loading velocity did not affect the deformation level in the negative pressure phase.

\section{Competing Interests}

The authors declare that they have no competing interests.

\section{Acknowledgments}

This work was supported by the National Research Foundation of Korea (NRF) grant funded by the Korea government (MSIP) (no. 2015R1A2A1A15052688). This work was supported by the National Research Foundation of Korea (NRF) grant funded by the Korea government (MSIP) through GCRC-SOP (no. 2011-0030013).

\section{References}

[1] T. Ngo, P. Mendis, A. Gupta, and J. Ramsay, "Blast loading and blast effects on structures-an overview," Electronic Journal of Structural Engineering, vol. 7, pp. 76-91, 2007.

[2] Y. Shi and M. G. Stewart, "Damage and risk assessment for reinforced concrete wall panels subjected to explosive blast loading," International Journal of Impact Engineering, vol. 85, pp. 5-19, 2015.

[3] B. Yan, F. Liu, D. Song, and Z. Jiang, "Numerical study on damage mechanism of RC beams under close-in blast loading," Engineering Failure Analysis, vol. 51, pp. 9-19, 2015.

[4] Q. Li, L. Qiao, G. Dasgupta, S. Ma, L. Wang, and J. Dong, "Blasting vibration safety criterion analysis with equivalent elastic boundary: based on accurate loading model," Shock and Vibration, vol. 2015, Article ID 604683, 10 pages, 2015.

[5] K. Spranghers, I. Vasilakos, D. Lecompte, H. Sol, and J. Vantomme, "Numerical simulation and experimental validation of the dynamic response of aluminum plates under free air explosions," International Journal of Impact Engineering, vol. 54, pp. 83-95, 2013.

[6] C. M. Morison, "Dynamic response of walls and slabs by singledegree-of-freedom analysis-a critical review and revision," International Journal of Impact Engineering, vol. 32, no. 8, pp. 1214-1247, 2006.

[7] Y. Qasrawi, P. J. Heffernan, and A. Fam, "Dynamic behaviour of concrete filled FRP tubes subjected to impact loading," Engineering Structures, vol. 100, pp. 212-225, 2015.

[8] C. Bedon, C. Amadio, and A. Sinico, "Numerical and analytical investigation on the dynamic buckling behavior of glass columns under blast," Engineering Structures, vol. 79, pp. 322340, 2014.

[9] K. Fischer and I. Häring, "SDOF response model parameters from dynamic blast loading experiments," Engineering Structures, vol. 31, no. 8, pp. 1677-1686, 2009.

[10] S. E. Rigby, A. Tyas, and T. Bennett, "Elastic-plastic response of plates subjected to cleared blast loads," International Journal of Impact Engineering, vol. 66, pp. 37-47, 2014.

[11] L. Jun and H. Hong, "Development of a simplified numerical method for structural response analysis to blast load," Procedia Engineering, vol. 14, pp. 2558-2566, 2011.

[12] T. Krauthammer and A. Altenberg, "Negative phase blast effects on glass panels," International Journal of Impact Engineering, vol. 24, no. 1, pp. 1-17, 2000.

[13] A. K. Chopra, Dynamic of Structures: Theory and Applications to Earthquake Engineering, Pearson Education, 3rd edition, 2007.

[14] O. R. Hansen and D. M. Johnson, "Improved far-field blast predictions from fast deflagrations, DDTs and detonations of vapour clouds using FLACS CFD," Journal of Loss Prevention in the Process Industries, vol. 35, pp. 293-306, 2015.

[15] O. R. Hansen, F. Gavelli, M. Ichard, and S. G. Davis, "Validation of FLACS against experimental data sets from the model evaluation database for LNG vapour dispersion," Journal of Loss Prevention in the Process Industries, vol. 23, pp. 857-877, 2010.

[16] M. H. Kim, B. J. Koo, R. M. Mercier, and E. G. Ward, "Ves$\mathrm{sel} / \mathrm{mooring} /$ riser coupled dynamic analysis of a turret-moored FPSO compared with OTRC experiment," Ocean Engineering, vol. 32, no. 14-15, pp. 1780-1802, 2005.

[17] J.-H. Hwang, M.-I. Roh, and K.-Y. Lee, "Determination of the optimal operating conditions of the dual mixed refrigerant cycle for the LNG FPSO topside liquefaction process," Computers and Chemical Engineering, vol. 49, pp. 25-36, 2013.

[18] F. Chille, J. R. Bakke, and K. V. Wingerden, "Use of CFD tools for prediction of explosion loads," in Proceedings of the Handling Exceptions in Structural Engineering, Roma, Italy, November 2008.

[19] ISO, "Glass in building - explosion-resistant security glazingtest and classification for arena air-blast loading," ISO 16933:2007, International Organization for Standardization (ISO), London, UK, 2007.

[20] UK Offshore Operators Association (UKOOA), Fire and Explosion Guidance Part 1: Avoidance and Mitigation of Explosions, UK Offshore Operators Association, London, UK, 2003.

[21] British Standards Institution, "Petroleum and natural gas industries-fixed steel offshore structures," BS EN ISO 19902, 2005. 
[22] U. S. Lee, S. H. Kim, and J. Y. Cho, "Dynamic analysis of the linear discrete dynamic systems subjected to the initial conditions by using an FFT-based spectral analysis method," Journal of Sound and Vibration, vol. 288, no. 1-2, pp. 293-306, 2005.

[23] A. S. Fallah and L. A. Louca, "Pressure-impulse diagrams for elastic-plastic-hardening and softening single-degree-offreedom models subjected to blast loading," International Journal of Impact Engineering, vol. 34, no. 4, pp. 823-842, 2007.

[24] X. Lin, Y. X. Zhang, and P. J. Hazell, "Modelling the response of reinforced concrete panels under blast loading," Materials and Design, vol. 56, pp. 620-628, 2014. 


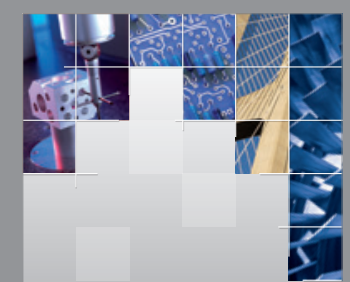

\section{Enfincering}
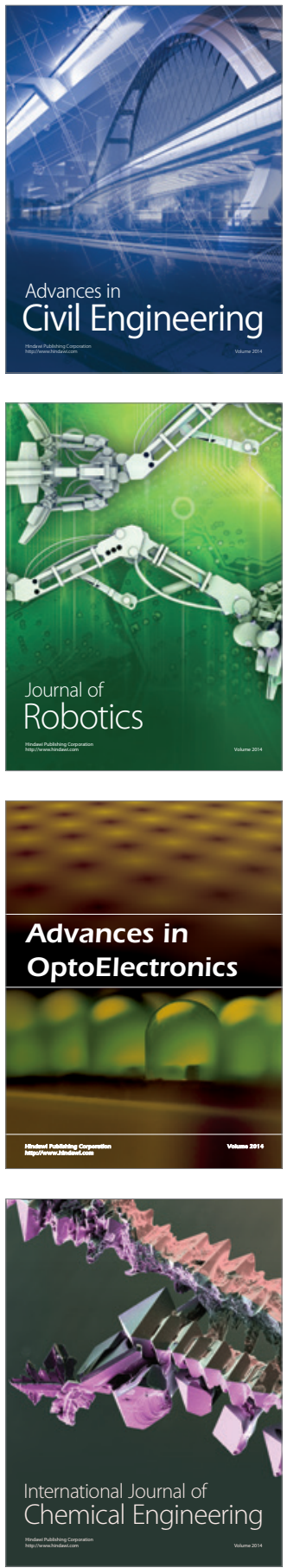

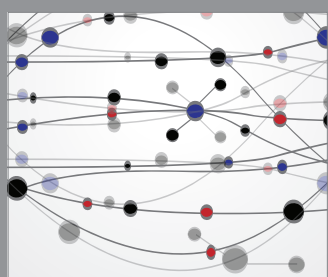

The Scientific World Journal

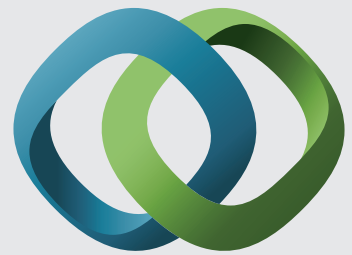

\section{Hindawi}

Submit your manuscripts at

http://www.hindawi.com
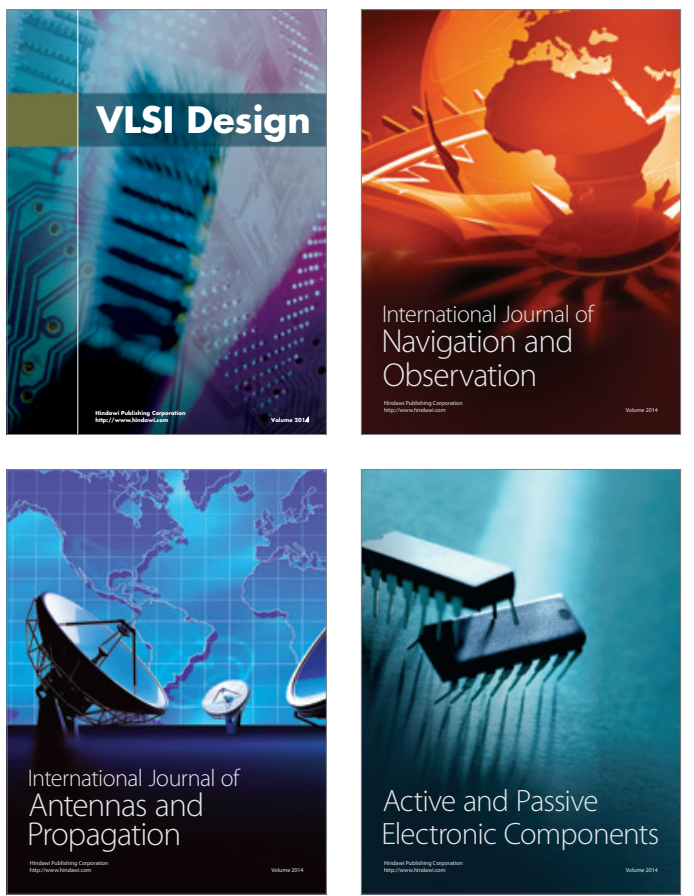
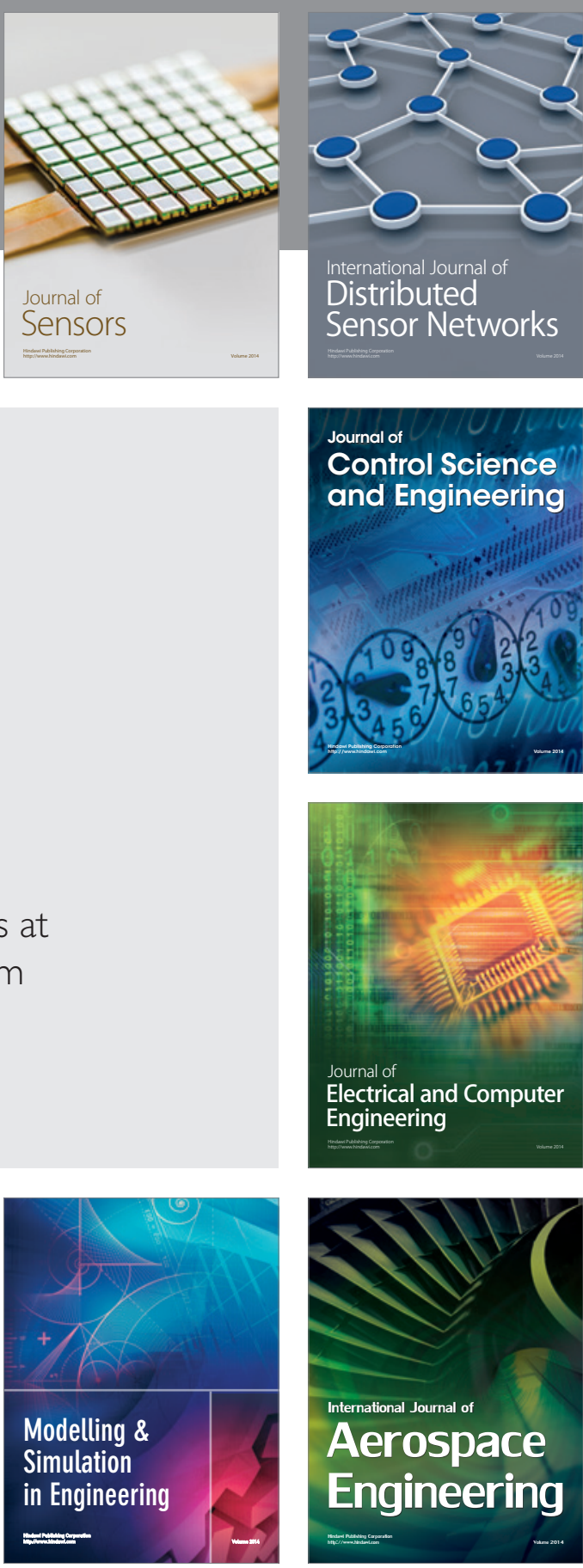

International Journal of

Distributed

Sensor Networks

Journal of

Control Science

and Engineering
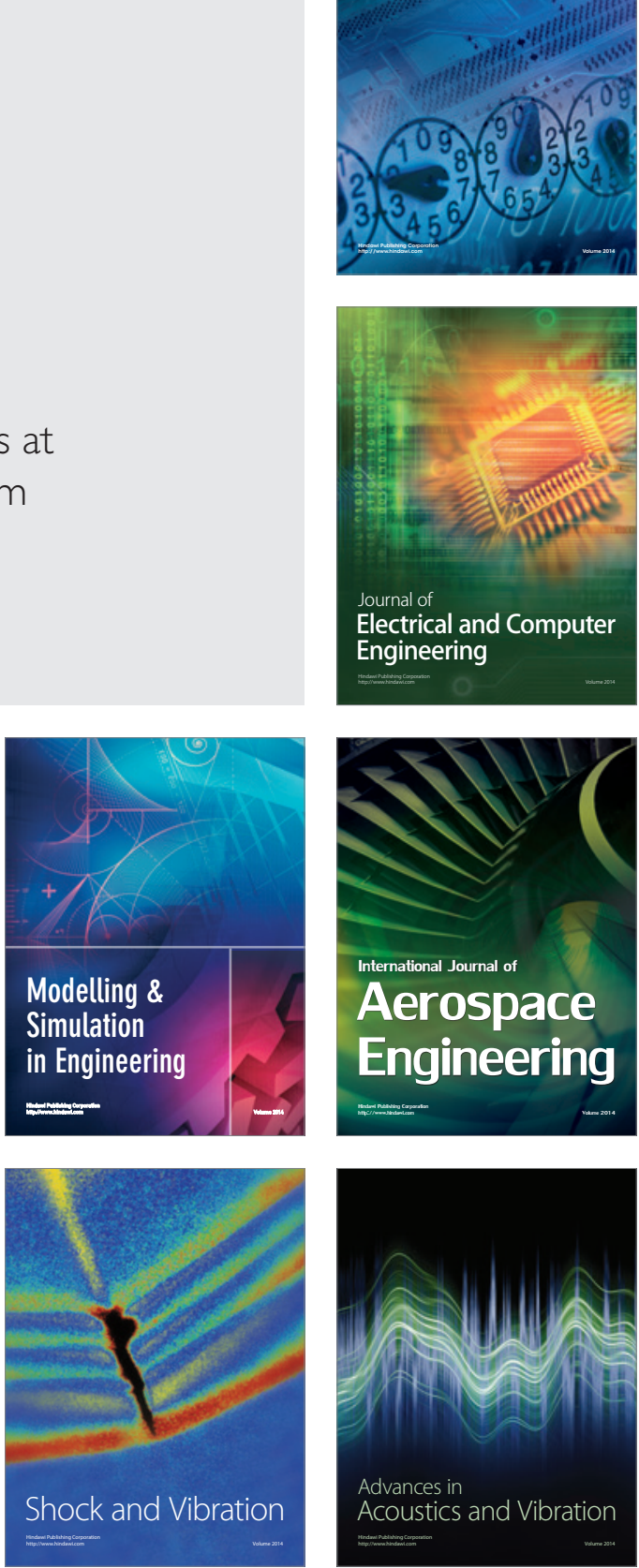